\title{
Evidence that the Brain of the Conscious Dog Is Insulin Sensitive
}

S. N. Davis, C. Colburn, R. Dobbins, S. Nadeau, D. Neal, P. Williams, and A. D. Cherrington

Departments of Medicine and Molecular Physiology and Biophysics, Vanderbilt University School of Medicine,

Nashville, Tennessee 37232

\begin{abstract}
The aim of this study was to determine whether a selective increase in the level of insulin in the blood perfusing the brain is a determinant of the counterregulatory response to hypoglycemia. Experiments were carried out on 15 conscious 18-h-fasted dogs. Insulin was infused $(2 \mathrm{mU} / \mathrm{kg}$ per min) in separate, randomized studies into a peripheral vein $(n=7)$ or both carotid and vertebral arteries $(n=8)$. This resulted in equivalent systemic insulinemia ( $84 \pm 6 \mathrm{vs} .86 \pm 6$ $\mu \mathrm{U} / \mathrm{ml}$ ) but differing insulin levels in the head (84 $\pm 6 \mathrm{vs}$. $195 \pm 5 \mu \mathrm{U} / \mathrm{ml}$, respectively). Glucose was infused during peripheral insulin infusion to maintain the glucose level $(56 \pm 2 \mathrm{mg} / \mathrm{dl})$ at a value similar to that seen during head insulin infusion $(58 \pm 2 \mathrm{mg} / \mathrm{dl})$. Despite equivalent peripheral insulin levels and similar hypoglycemia; steady state plasma epinephrine $(792 \pm 198 \mathrm{vs} .2394 \pm 312 \mathrm{pg} / \mathrm{ml})$, norepinephrine $(404 \pm 33$ vs. $778 \pm 93 \mathrm{pg} / \mathrm{ml})$, cortisol $(6.8 \pm 1.8 \mathrm{vs}$. $9.8 \pm 1.6 \mu \mathrm{g} / \mathrm{dl})$ and pancreatic polypeptide $(722 \pm 273 \mathrm{vs}$. $1061 \pm 255 \mathrm{pg} / \mathrm{ml}$ ) levels were all increased to a greater extent during head insulin infusion $(P<0.05)$. Hepatic glucose production, measured with $\left[3-{ }^{3} \mathrm{H}\right]$ glucose, rose from $2.6 \pm 0.2$ to $4.3 \pm 0.4 \mathrm{mg} / \mathrm{kg}$ per $\min (P<0.01)$ in response to head insulin infusion but remained unchanged $(2.6 \pm 0.5$ $\mathrm{mg} / \mathrm{kg}$ per min) during peripheral insulin infusion. Similarly, gluconeogenesis, lipolysis, and ketogenesis were increased twofold $(P<0.001)$ during head compared with peripheral insulin infusion. Cardiovascular parameters were also significantly higher $(P<0.05)$ during head compared with peripheral insulin infusion. We conclude that during hypoglycemia in the conscious $\operatorname{dog}(a)$ the brain is directly responsive to physiologic elevations of insulin and (b) the response includes a profound stimulation of the autonomic nervous system with accompanying metabolic and cardiovascular changes. (J. Clin. Invest. 1995. 95:593-602.) Key words: hypoglycemia - epinephrine $\cdot$ autonomic nervous system • gluconeogenesis • lipolysis
\end{abstract}

\section{Introduction}

The brain, via the autonomic nervous system (ANS),${ }^{1}$ controls many diverse homeostatic processes. To what extent this in-

Address correspondence to S. N. Davis, Department of Medicine, Vanderbilt University School of Medicine, B-3307 Medical Center North, Nashville, TN 37232-2230. Phone: 615-322-3008; FAX: 615-322-2198.

Received for publication 1 November 1993 and in revised form 10 October 1994.

1. Abbreviations used in this paper: ANS, autonomic nervous system; NEFA, non-esterified fatty acid.

J. Clin. Invest.

(C) The American Society for Clinical Investigation, Inc.

0021-9738/95/02/0593/10 \$2.00

Volume 95, February 1995, 593-602 cludes direct regulation of metabolism is poorly understood and often debated. One reason for this controversy is the lack of evidence from studies on conscious subjects that circulating insulin, the major regulator of carbohydrate, fat, and protein metabolism, exerts direct effects upon the brain. Previous in vitro studies have been divided on whether insulin can influence cerebral glucose utilization (1-6). This has tended to reinforce the classical belief that the brain is an insulin-insensitive organ. However, this view has been widely challenged. Insulin receptors have been demonstrated in widespread regions of the brain $(7,8)$, thereby providing a mechanism for direct insulin action. Furthermore high affinity insulin receptors have also been reported in brain microvessels which provide a pathway for blood borne insulin to cross the blood-brain barrier and activate insulin receptors within the brain (9). Insulin when injected into the carotid artery of anesthetized dogs (10) and rats, in the absence of hypoglycemia, produced cardiovascular (10), and systemic metabolic changes (11). In addition, microinjection of insulin into specific regions of the rat brain (12-13) (hypothalamus and preoptic area) has also resulted in systemic changes in carbohydrate and lipid metabolism. Nevertheless, despite the above reports and data indicating that certain forms of obesity may be due to defective brain insulin responsiveness $(8,14)$, convincing data are lacking from conscious subjects which demonstrate direct physiologic effects of blood-borne insulin on the brain.

We have recently demonstrated in conscious dogs (15) and normal human (16) that increased insulin levels can amplify the ANS (epinephrine and norepinephrine) response to a given hypoglycemia. Kerr et al. (17) and Davis et al. (18) have also demonstrated amplification of the sympathetic nervous system response to hypoglycemia by insulin in insulin-dependent diabetic human. Other studies, in which microneurography was used, have demonstrated that insulin can increase sympathetic nerve activity even under euglycemic conditions $(19,20)$. However, it has been argued that the increase in sympathetic nerve activity during hyperinsulinemic euglycemia may be due to baroreceptor responses to insulin induced vasodilation rather than direct insulin effects upon the central nervous system (19). Thus, the site of insulin sensing could not be identified from the above studies. A hypothesis which would bring together the above data would be one which proposes that activation of the ANS results from the brain directly responding to the circulating insulin level. This hypothesis, previously suggested by Szabo and Szabo (11), although plausible has not been definitively tested in the conscious animal. The aim of the present study therefore was to determine in conscious normal dogs whether a selective, physiologic increment in the insulin level of the blood perfusing the brain could amplify the neuroendocrine response to hypoglycemia.

\section{Methods}

Animals. Experiments were carried out on 15 normal, conscious 18 -hfasted dogs of either sex (weight $20.3-24.9 \mathrm{~kg}$, mean $22 \pm 0.4 \mathrm{~kg}$ ), 
which were fed a meat and chow diet (31\% protein, $52 \%$ carbohydrate, $11 \%$ fat, $6 \%$ fiber; Kal Kan meat and Wayne dog chow) once daily for 3-4 wk before each study. The dogs were housed in a surgical facility that met the guidelines of the American Association for the Accreditation of Laboratory Animal Care, and the protocols were approved by the Vanderbilt University Medical Center Animal Care Committee.

Surgical procedures. $16 \mathrm{~d}$ before each experiment, catheters were inserted into a hepatic vein, the portal vein and a femoral artery under general anesthesia as previously described (21). One week later each animal underwent a second operation (again under general anesthesia) during which silastic catheters were placed into both carotid and vertebral arteries and a jugular vein as previously described (22). The catheters were filled with heparinized saline, knotted, and placed into subcutaneous pockets. Due to problems in availability Doppler flow probes (Instrumentation Development Laboratories, Baylor College of Medicine, Houston, Texas) were placed around the portal vein and the hepatic artery in only eight dogs. On the day of the experiment the catheters and doppler leads were exteriorized from their subcutaneous pockets (under local anesthesia, 2\% lidocaine; Astra, Worcester, MA). The contents of each catheter were aspirated, and heparinized saline (1 U/ $\mathrm{ml}$ ) was infused into them at a slow rate $(0.1 \mathrm{ml} / \mathrm{min})$. Blood was subsequently sampled from the arterial, portal vein, and hepatic vein catheters. Insulin was administered via both carotid and vertebral arteries or a percutaneous catheter inserted into a cephalic vein. As insulin is neither extracted, sequestered, or synthesized by the brain to any appreciable amounts any insulin infused directly into the carotid and vertebral arteries will traverse the head and overflow into the systemic circulation. Consequently, systemic insulin levels obtained during a constant infusion into the carotid and vertebral arteries would be expected to be equivalent to systemic levels obtained during an identical peripheral rate of insulin administration. When insulin was administered peripherally saline was administered at an equivalent rate into both carotid and both vertebral arteries. In this way, each dog received equivalent infusions of fluid into the head during each experiment. Radioactive tracers, indocyanine green, and glucose were administered via a catheter in the other cephalic vein.

Experimental design. Each experiment consisted of a tracer equilibration ( $-120--40 \mathrm{~min})$, a control ( $-40-0 \mathrm{~min})$ and an experimental period $(0-180 \mathrm{~min})$. A priming dose of purified $\left[3-{ }^{3} \mathrm{H}\right]$ glucose $(50$ $\mu \mathrm{Ci}$ ) was given at $-120 \mathrm{~min}$, followed by a continuous infusion of $\left[3-{ }^{3} \mathrm{H}\right.$ ] glucose $(0.67 \mu \mathrm{Ci} / \mathrm{min}),\left[\mathrm{U}-{ }^{14} \mathrm{C}\right]$ alanine $(0.67 \mu \mathrm{Ci} / \mathrm{min})$ and indocyanine green $\left(0.1 \mathrm{mg} \cdot \mathrm{m}^{-2} \cdot \mathrm{min}^{-1}\right)$. Potassium phosphate supplementation ( $2 \mathrm{gm}$ per dog) was administered during both limbs of the study. In separate randomized experiments insulin was infused at the rate of $2 \mathrm{mU} / \mathrm{kg}$ per min into the vertebral and carotid arteries $(n=8)$ or a peripheral vein $(n=7)$. The rate of fall of glucose and the hypoglycemic plateau were equated in the two groups by a modification of the glucose clamp technique in which plasma glucose was sampled every $5 \mathrm{~min}$ (23). Arterial blood samples for hormone and metabolite assessment were taken every $10 \mathrm{~min}$ throughout the control period and every 15 min during the experimental period. Portal and hepatic vein blood samples were taken at 20 -min intervals throughout the control period and at 30-min intervals during the experimental period.

Collection and processing of samples. The collection and processing of blood samples have been described elsewhere, as have the methods of column chromatography used for the determinations of the $\left[{ }^{14} \mathrm{C}\right]$ alanine and $\left[{ }^{14} \mathrm{C}\right]$ lactate specific activities (24).

Plasma glucose concentrations were measured in quadruplicate using the glucose oxidase method in a Beckman Glucose Analyzer II (Fullerton, CA). Whole blood alanine lactate, glycerol, and 3-hydroxybutyrate concentrations were determined in samples deproteinized with $4 \%$ (wt/ vol) perchloric acid (PCA; $1 \mathrm{ml}$ blood $+3 \mathrm{ml} \mathrm{PCA}$ ) with the method developed by Lloyd et al. (25) for the Technicon Autoanalyzer. Blood acetoacetate levels were determined on the above supernatant with a spectrophotometric assay (26). Plasma non-esterified fatty acid (NEFA) concentrations were determined according to the method of Ho (27). Immunoreactive glucagon was measured according to the method of Aguilar-Parada et al. (28) with an interassay C.V. of $15 \%$. Immunoreactive insulin was measured as described previously (29) with an in- terassay C.V. of $11 \%$. Catecholamines were determined by HPLC (30) with an interassay C.V. of $17 \%$ for epinephrine and $14 \%$ for norepinephrine. Two modifications in the procedure for catecholamine determination were made. (a) A five-rather than one-point standard calibration curve was used; $(b)$ aliquots of the initial and final samples of plasma were spiked with known amounts of epinephrine and norepinephrine so that accurate identification of the respective catecholamine peaks could be made. Cortisol was assayed using the Clinical Assays Gamma Coat RIA Kit with an interassay C.V. of $6 \%$. Pancreatic polypeptide was measured using the method of Hagopian et al. (31) with an interassay C.V. of $8 \%$.

Materials. $\left[3-{ }^{3} \mathrm{H}\right.$ ]glucose (New England Nuclear, Boston, MA) was used as the glucose tracer $(11.5 \mathrm{mCi} / \mathrm{mmol})$ and $\left[\mathrm{U}-{ }^{14} \mathrm{C}\right]$ alanine (ICN, Irvine, CA) was used as the labeled gluconeogenic precursor $(150 \mathrm{mCi} / \mathrm{mmol}$ ). Insulin was purchased from Eli Lilly (Indianapolis, IN). The insulin infusion solution was prepared with normal saline and contained 3\% ( $\mathrm{vol} / \mathrm{vol})$ of the dogs own plasma. Glucagon ${ }^{125} \mathrm{I}$-tracer was obtained from NOVO (Bagsvaerd, Denmark), and glucagon for the standard curves was purchased from Sigma (St. Louis, MO). D-50W (Abbot) was used for infusion into a peripheral vein when necessary. Indocyanine green was purchased from Hynson, Westcott and Dunning (Baltimore, MD).

Tracer methods and calculations. The net hepatic balance of each substrate (blood lactate, alanine, glycerol, acetoacetate, 3-hydroxybutyrate and plasma glucose and NEFA was calculated with the formula $\left\{H_{v}-\left(0.2 a+0.8 p_{v}\right\} Q\right.$, where $a, p_{v}$, and $H_{v}$ are the arterial portal vein and hepatic vein concentrations, and $Q$ is the flow (blood or plasma as required) to the liver as determined by the use of Indocyanine green. All hepatic balances are depicted as positive values, but are labeled appropriately as either output or uptake. The proportion of the hepatic blood supply provided by the hepatic artery was assumed to be $20 \%$ based on mean data obtained from doppler flow probes placed on the hepatic artery and portal vein $(n=8 \mathrm{dogs})$. The increase in hepatic blood flow observed during hypoglycemia in the present experiments was due to proportional changes in both portal vein and hepatic artery flows which is consistent with previous findings (32).

The rates of tracer determined glucose appearance $\left(R_{\mathrm{a}}\right)$ and utilization $\left(R_{\mathrm{d}}\right)$ were calculated according to the methods of Wall et al. (33) as simplified by Debodo et al. (34). $R_{\mathrm{a}}$ is comprised of both endogenous (hepatic) glucose production and the exogenous glucose infusion. By subtracting the total amount of exogenous glucose infused from total $R_{\mathrm{a}}$, hepatic glucose production can be derived. It is now recognized that this model is not fully quantitative, as underestimates of total $R_{\mathrm{a}}$ and $R_{\mathrm{d}}$ can be obtained. By using a highly purified tracer and making measurements under steady state conditions (i.e., constant specific activity) these problems can be minimized. The hepatic $\left[{ }^{14} \mathrm{C}\right]$ glucose production rate, a measure of the overall gluconeogenic rate, was determined using the tracer technique as described elsewhere (35).

The efficiency of the hepatic conversion of alanine to glucose, which reflects the intrahepatic gluconeogenic process, was calculated by dividing the $\left[{ }^{14} \mathrm{C}\right]$ glucose production by the rate of net $\left[{ }^{14} \mathrm{C}\right]$ alanine and $\left[{ }^{14} \mathrm{C}\right]$ lactate uptake by the liver. This parameter is a minimal estimate of the actual efficiency since the ${ }^{14} \mathrm{C}$-specific activity in the gluconeogenic precursor pool within the hepatocyte is diluted at the oxalo acetate level. The overall gluconeogenic rate ( $\mu \mathrm{mol} / \mathrm{kg}$ per $\mathrm{min})$ can be estimated in two ways. One can assume that all of the gluconeogenic precursors extracted by the liver are completely converted to glucose and thereby calculate a maximal estimate of this process. To do this in the present study, the net uptake of pyruvate was assumed to be $1 / 10$ that of lactate (36) and the net uptake of gluconeogenic amino acids other than alanine was assumed to be equivalent to that of alanine (37). Alternatively, the net hepatic uptake of all gluconeogenic precursors can be multiplied by the calculated gluconeogenic efficiency to give a minimal estimate of the process. The contribution of gluconeogenesis to overall glucose production can then be calculated by dividing either of the above by 2 to account for the incorporation of the C-3 precursors into the C-6 glucose molecule and then dividing this quotient by the net hepatic glucose balance ( $\mu \mathrm{mol} / \mathrm{kg}$ per min) and multiplying by 100 . In this way quantitative brackets can be given to the gluconeogenic process. 
Statistical analysis. Data are expressed as means \pm SE unless otherwise stated, and analyzed using standard, parametric two way analysis of variance with a repeated measures design. This was coupled with the paired students $t$ test to delineate at which time statistical significance was reached. A value of $P<0.05$ indicated significant difference.

\section{Results}

Insulin, glucose, and counterregulatory hormone levels. Insulin infusions resulted in equivalent steady state levels by $60 \mathrm{~min}$ in head and peripheral administration studies. During the final $120 \mathrm{~min}$ of each experiment, systemic arterial insulin levels were stable ( $\mathrm{CV}$ during head infusion $=3.6 \%, \mathrm{CV}$ during peripheral infusions $=3.0 \%$ ) at $84 \pm 6$ and $86 \pm 6 \mu \mathrm{U} / \mathrm{ml}$ for head and peripheral infusions respectively. Basal insulin levels were similar in each group $(12 \pm 2 \mu \mathrm{U} / \mathrm{ml})$. As insulin is neither extracted nor sequestered by the brain, jugular vein insulin levels can serve as an accurate measure of the cerebral insulin concentration. In the present study, the jugular vein insulin level was measured in three animals and found to be $195 \pm 5 \mu \mathrm{U} / \mathrm{ml}$ during carotid and vertebral insulin infusion, a value close to the predicted estimate (22) given the infusion rate used. Glucose was infused in the peripheral insulin infusion group so as to equate the rate of fall $(1.07 \mathrm{mg} / \mathrm{min})$ and the plateau glucose level ( $58 \pm 2$ vs. $56 \pm 2 \mathrm{mg} / \mathrm{dl}$ ) in the head and peripheral infusion groups respectively (Fig. 1). The glucose infusion rate was increased slowly to $2.0 \pm 0.3 \mathrm{mg} / \mathrm{kg}$ per $\mathrm{min}$ by $90 \mathrm{~min}$ and then was maintained at this rate for the remainder of the 180 min experimental period. The stability of the plasma glucose level during the last $60 \mathrm{~min}$ of each protocol was demonstrated by a C.V. of $1.1 \pm 0.1 \%$.

In response to hypoglycemia the plasma levels of the counterregulatory hormones (epinephrine, norepinephrine, cortisol, glucagon) and pancreatic polypeptide all increased compared with baseline $(P<0.001)$. Despite similar hypoglycemia, epinephrine (Fig. 2) increased significantly more during head (basal $240 \pm 51$ to $2394 \pm 312 \mathrm{pg} / \mathrm{ml}$ ) than peripheral (basal $180 \pm 45$ to $792 \pm 198, P<0.001)$ insulin infusion. Similarly plasma norepinephrine $(303 \pm 50$ to $778 \pm 93$ vs. $258 \pm 48$ to $404 \pm 33 \mathrm{pg} / \mathrm{ml}, P<0.01)$ and cortisol $(2.7 \pm 0.6$ to $9.8 \pm 1.6$ vs. $1.5 \pm 0.3$ to $6.3 \pm 1.8 \mu \mathrm{g} / \mathrm{dl}, P<0.05)$ were also significantly increased during the head compared to peripheral insulin infusions. Pancreatic polypeptide, an indirect marker of parasympathetic activity, also increased to a greater extent during the head insulin infusion ( $219 \pm 53$ to $1061 \pm 64$ vs. $251 \pm 64$ to $722 \pm 273$ $\mathrm{pg} / \mathrm{ml}, P<0.05)$. Unlike the preceding counterregulatory hormones there was no significant difference in the plasma glucagon responses in the two protocols (Fig. 3).

Glucose flux. Glucose specific activity $(\mathrm{dpm} / \mathrm{mg})$ was in a similar steady state during the control period of the head and peripheral insulin infusions (C.V. of glucose specific activity $=1.5 \%$ head and $1.7 \%$ peripheral). Table I demonstrates the time course of the change in glucose specific activity. By the final $60 \mathrm{~min}$ of each insulin infusion period, an isotopic steady state existed with a C.V. of 0.7 and $2.9 \%$ in the head and peripheral groups respectively. Hepatic glucose production (Fig. 4) was initially similar (2.6 $\pm 0.4 \mathrm{mg} / \mathrm{kg}$ per $\mathrm{min}$ ) in both groups, remained unchanged $(2.6 \pm 0.5 \mathrm{mg} / \mathrm{kg}$ per $\mathrm{min})$ during peripheral infusion but increased during head infusion ( $4.3 \pm 0.4$ $\mathrm{mg} / \mathrm{kg}$ per min, $P<0.001)$. This response was confirmed by the A-V difference data (Table II).

Glucose utilization increased as the plasma glucose fell during the first $45 \mathrm{~min}$ of hormone infusion in both protocols. When
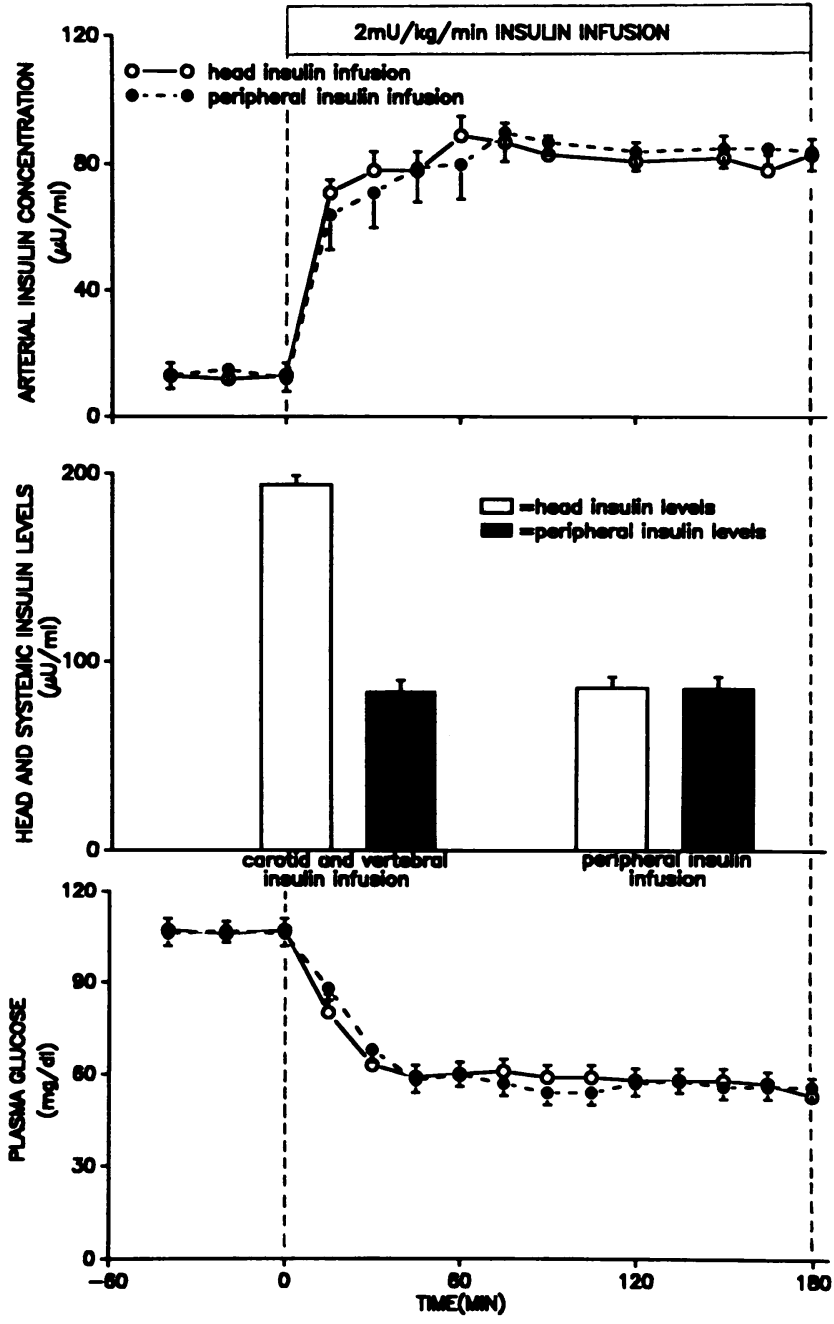

Figure 1. Effects of $2 \mathrm{mU} / \mathrm{kg}$ per min insulin infusions delivered either into both carotid and vertebral arteries (head insulin level 195 $\pm 5 \mu \mathrm{U} /$ $\mathrm{ml}$ ) or a peripheral vein on arterial plasma insulin (insulin level $86 \pm 6$ $\mu \mathrm{U} / \mathrm{ml}$ ) and glucose concentrations in conscious overnight fasted dogs.

the glucose level had stabilized the rates of glucose utilization $(4.3 \pm 0.3$ vs. $4.6 \pm 0.5 \mathrm{mg} / \mathrm{kg}$ per $\mathrm{min})$ and clearance $(7.6 \pm 0.6$ vs. $7.8 \pm 0.7 \mathrm{ml} / \mathrm{kg}$ per $\mathrm{min}$ ) were similar during both head and peripheral insulin infusions.

Gluconeogenic precursor metabolism. Hepatic blood flow was similar at the start of the head and peripheral insulin infusions ( $28 \pm 2$ vs. $36 \pm 6 \mathrm{ml} / \mathrm{kg}$ per min, respectively). It remained at basal levels during peripheral infusion but increased significantly to $44 \pm 4 \mathrm{ml} / \mathrm{kg} / \mathrm{min}(P<0.001)$ during head insulin infusion. Arterial blood lactate levels were increased $(P<$ 0.001 ) by a greater amount during the steady state period of head $(958 \pm 159$ to $3238 \pm 654 \mu \mathrm{M})$ compared to peripheral insulin infusion $(798 \pm 122$ to $1103 \pm 302 \mu \mathrm{M})$. The liver switched from net hepatic production of lactate to net hepatic uptake during both insulin infusion protocols. By the last hour of hypoglycemia, however, net hepatic lactate uptake was significantly increased during head $(-8.0 \pm 2.2$ to $23.8 \pm 4.6 \mu \mathrm{mol} / \mathrm{kg}$ per $\min )$ compared with peripheral insulin infusion $(-12.5 \pm 5.0$ to $7.7 \pm 2.2 \mu \mathrm{mol} / \mathrm{kg}$ per $\mathrm{min}), P<0.001$.

Arterial blood glycerol levels increased by a significantly greater amount $(P<0.001)$ during head $(102 \pm 20$ to $467 \pm 78$ 


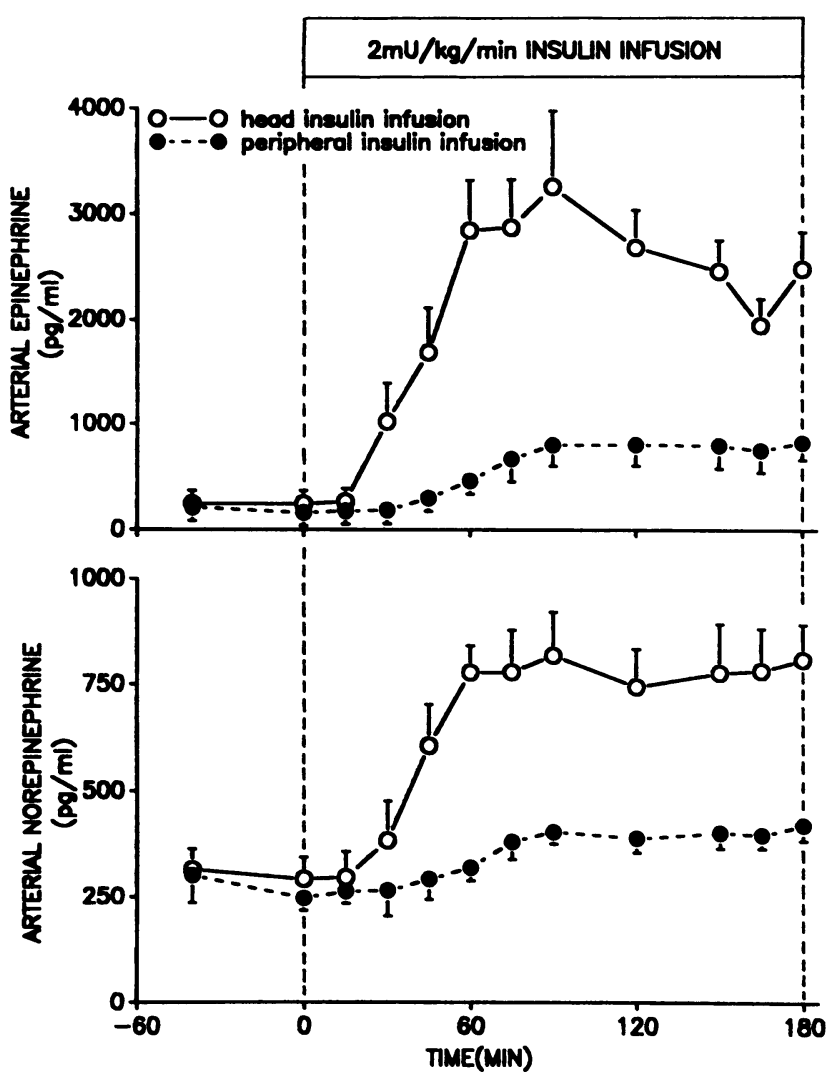

Figure 2. Effects of $2 \mathrm{mU} / \mathrm{kg}$ per min insulin infusions delivered either into both carotid and vertebral arteries (head insulin level 195 $\pm 6 \mu \mathrm{U} /$ $\mathrm{ml}$ ) or a peripheral vein (insulin level $86 \pm 6 \mu \mathrm{U} / \mathrm{ml}$ ) in the presence of hypoglycemia on arterial plasma epinephrine and norepinephrine in conscious overnight fasted dogs. Head values are significantly increased $(P<0.001)$ compared with peripheral values.

$\mu \mathrm{M})$ compared with peripheral $(70 \pm 21$ to $209 \pm 25 \mu \mathrm{M})$ insulin infusion. Net hepatic glycerol uptake was also significantly $(P$ $<0.001)$ increased during head $(1.9 \pm 0.4$ to $14.3 \pm 3.6 \mu \mathrm{mol} /$ $\mathrm{kg}$ per $\mathrm{min}$ ) compared with peripheral insulin infusion (1.9 \pm 0.8 to $4.7 \pm 1.1 \mu \mathrm{mol} / \mathrm{kg}$ per $\mathrm{min}$ ). Fractional extraction of glycerol was equivalent in both protocols $(67 \pm 5 \%)$ and did not change throughout the study.

Arterial blood alanine levels fell similarly during head $(401 \pm 33$ to $234 \pm 29 \mu \mathrm{M})$ and peripheral insulin infusion (354 \pm 51 to $176 \pm 23 \mu \mathrm{M}$ ). Due to increased hepatic blood flow and therefore a greater delivered load, net hepatic uptake of alanine increased significantly during head infusion $(2.8 \pm 0.3$ to $5.9 \pm 0.9 \mu \mathrm{mol} / \mathrm{kg}$ per min, $P<0.001$ ) but remained at control rates during peripheral insulin infusion $(2.9 \pm 0.4$ to $2.8 \pm 0.4 \mu \mathrm{mol} / \mathrm{kg}$ per min). Fractional extraction of alanine, however, increased similarly during head $(40 \pm 5$ to $67 \pm 4 \%)$ and peripheral insulin infusion ( $28 \pm 4$ to $54 \pm 4 \%)$.

Gluconeogenic parameters. The efficiency with which the liver converted alanine and lactate to glucose (Table V) increased similarly during head ( $25 \pm 9$ to $53 \pm 9 \%)$ and peripheral insulin infusion $(20 \pm 8$ to $44 \pm 8 \%)$. During the last hour of head insulin infusion, gluconeogenesis contributed minimal and maximal estimates of 2.5 and $4.3 \mathrm{mg} / \mathrm{kg}$ per min of total hepatic glucose production. During the last hour of peripheral insulin infusion these estimates were 0.8 and $1.8 \mathrm{mg} / \mathrm{kg}$ per $\mathrm{min}$, respectively. Thus with the head enriched with insulin gluconeo-

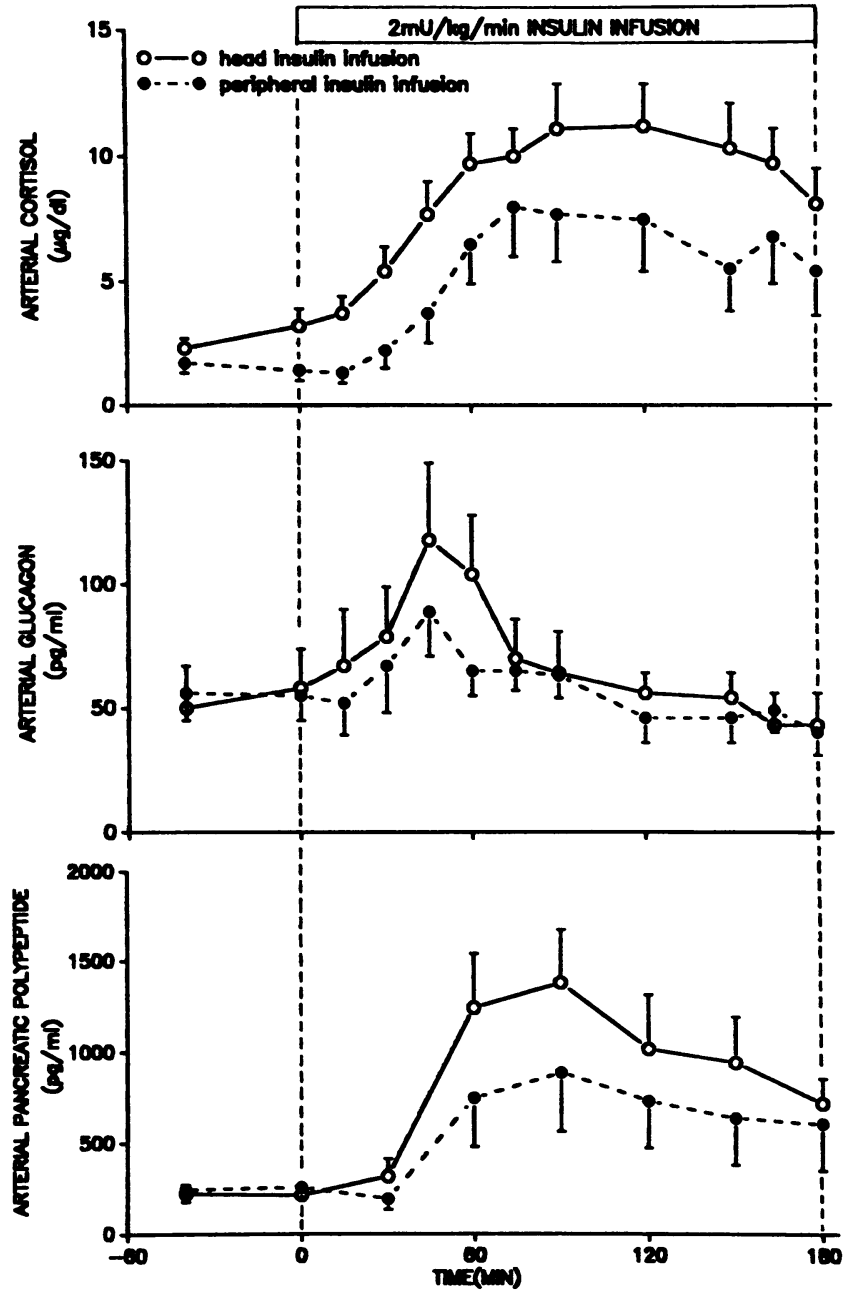

Figure 3. Effects of $2 \mathrm{mU} / \mathrm{kg}$ per $\mathrm{min}$ insulin infusions delivered either into both carotid and vertebral arteries (head insulin level $195 \pm 5 \mu \mathrm{U} /$ $\mathrm{ml}$ ) or a peripheral vein (insulin level $86 \pm 6 \mu \mathrm{U} / \mathrm{ml}$ ) in the presence of hypoglycemia on arterial plasma cortisol, glucagon and pancreatic polypeptide concentrations. Head values for cortisol and pancreatic polypeptide are significantly increased $(P<0.05)$ compared with peripheral values.

genesis contributed 65 to $100 \%$ of glucose production as opposed to 32 to $72 \%$ when the brain was not insulin enriched.

Ketone body and non-esterified fatty acid (NEFA) metabolism. Plasma NEFA levels (Table III) increased by a significantly greater amount $(P<0.05)$ during head $(774 \pm 124$ to $1130 \pm 145 \mu \mathrm{M})$ compared to peripheral insulin infusion $(714 \pm 100$ to $866 \pm 142 \mu \mathrm{M})$. Net hepatic uptake of NEFA (Table IV) was also significantly increased $(P<0.001)$ during head (3.2 \pm 0.8 to $9.5 \pm 2.1 \mu \mathrm{mol} / \mathrm{kg}$ per min) compared with peripheral infusion $(2.3 \pm 0.5$ to $3.6 \pm 0.9 \mu \mathrm{mol} / \mathrm{kg}$ per min). Hepatic fractional extraction of NEFA remained at basal levels during peripheral insulin infusion $(15 \pm 3 \%)$ but increased significantly during head insulin infusion $(18 \pm 3$ to $26 \pm 4 \%, P$ $<0.01$ ).

Blood acetoacetate and 3-hydroxybutyrate levels remained at basal levels during both insulin infusion protocols (Table III). Net hepatic production of ketone bodies did not change during the peripheral insulin infusions but increased significantly during head insulin infusion (Acetoacetate $1.0 \pm 0.3$ to 
Table I. Effects of Head and Peripheral Insulin Infusions (2 mU/kg per min) and the Resulting Hypoglycemia (58 $2 \mathrm{mg} / \mathrm{dl}$ ) on GlucoseSpecific Activity Obtained with Constant Infusions of $\left[3{ }^{3} \mathrm{H}\right]$ Glucose in Overnight-fasted Conscious Dogs

\begin{tabular}{|c|c|c|c|c|c|c|c|c|c|c|c|c|}
\hline \multirow{2}{*}{$\begin{array}{c}\text { Specific } \\
\text { activity } \\
(\mathrm{dpm} / \mathrm{mg})\end{array}$} & \multicolumn{4}{|c|}{ Control period } & \multicolumn{8}{|c|}{ Duration of hypoglycemia (min) } \\
\hline & -30 & -20 & -10 & 0 & 30 & 60 & 90 & 120 & 135 & 150 & 165 & 180 \\
\hline $\begin{array}{l}\text { Peripheral } \\
\text { infusion } \\
\text { Head }\end{array}$ & $6020 \pm 300$ & $5860 \pm 290$ & $5880 \pm 300$ & $5780 \pm 280$ & $6438 \pm 345$ & $4475 \pm 525$ & $4030 \pm 218$ & $3580 \pm 300$ & $3320 \pm 300$ & $3350 \pm 210$ & $3320 \pm 220$ & $3360 \pm 220$ \\
\hline infusion & $6460 \pm 300$ & $6350 \pm 300$ & $6250 \pm 300$ & $6300 \pm 310$ & $5880 \pm 610$ & $4190 \pm 380$ & $4060 \pm 540$ & $3890 \pm 380$ & $3830 \pm 400$ & $3890 \pm 450$ & $3870 \pm 500$ & $3850 \pm 400$ \\
\hline
\end{tabular}

$1.9 \pm 0.6 \mu \mathrm{mol} / \mathrm{kg}$ per $\mathrm{min}, 3$-hydroxybutyrate $1.0 \pm 0.4$ to $2.7 \pm 1.0 \mu \mathrm{mol} / \mathrm{kg}$ per min, both $P<0.01$ ).

Cardiovascular parameters. Heart rate (Fig. 5) increased to a greater extent $(P<0.01)$ during head compared to peripheral insulin infusion ( $103 \pm 13$ to $141 \pm 7$ vs. $79 \pm 8$ to $96 \pm 7$ bts/ min, respectively). Systolic blood pressure fell less during head

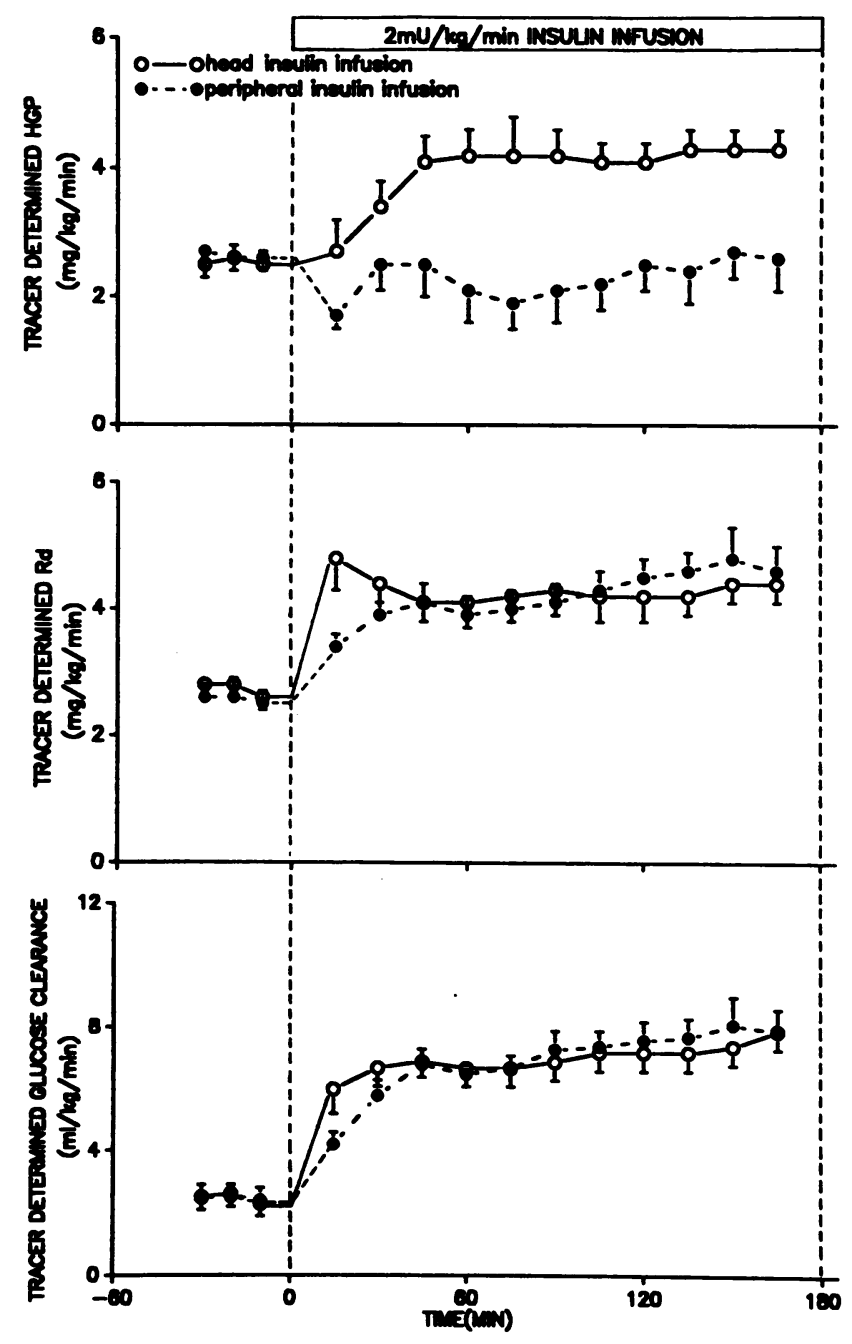

Figure 4. Effects of $2 \mathrm{mU} / \mathrm{kg}$ per min insulin infusions delivered either into both carotid and vertebral arteries (head insulin level $195 \pm 5 \mu \mathrm{U} /$ $\mathrm{ml}$ ) or a peripheral vein (insulin level $86 \pm 6 \mu \mathrm{U} / \mathrm{ml}$ ) in the presence of hypoglycemia on tracer determined hepatic glucose production (HGP), glucose utilization $\left(R_{d}\right)$ and glucose clearance in conscious overnight fasted dogs. Head values for HGP are significantly increased $(P<0.01)$ compared to peripheral values. insulin infusion ( $158 \pm 9$ to $147 \pm 7$ vs. $156 \pm 6$ to $138 \pm 8 \mathrm{mmHg}$, respectively). Diastolic blood pressure was maintained at control period values during the head insulin infusion $(68 \pm 5$ to $69 \pm 5 \mathrm{mmHg}$ ), whereas it fell during peripheral insulin administration ( $69 \pm 6$ to $53 \pm 4 \mathrm{mmHg}, P<0.05$ ). Consequently, mean arterial pressure was significantly greater $(P<0.05)$ during head compared with peripheral insulin infusion $(95 \pm 5 \mathrm{vs} .81 \pm 4$ $\mathrm{mmHg}$ ).

\section{Discussion}

Whether insulin has any direct effects upon the brain in vivo has long been debated. Previous in vitro studies have provided conflicting results $(1-6)$, whereas in vivo studies have not addressed this question directly in conscious subjects. The purpose of this study was to evaluate whether differing physiologic blood-borne insulin levels in the blood reaching the head would alter counterregulation in response to moderate fixed hypoglycemia in normal conscious dogs. The results clearly demonstrate that despite identical hypoglycemia and peripheral insulin levels the counterregulatory response was amplified when insulin was administered directly into the cerebral rather than peripheral circulation. A physiologic increment in insulin of $\sim 110 \mu \mathrm{U} /$ $\mathrm{ml}$ in the blood perfusing the brain resulted in increased sympathetic nervous activity ( $\uparrow$ epinephrine and norepinephrine levels), parasympathetic nervous activity ( $\uparrow$ pancreatic polypeptide levels), cortisol levels, heart rate, blood pressure, hepatic glucose production, lipolysis, gluconeogenesis and ketogenesis.

To allow the conclusion that the brain was the site of increased insulin sensing, we were extremely careful to control for other confounding variables. The systemic glucose and insulin levels were kept equivalent over time in the two protocols, thus precluding the argument that they provided the signal for the response. This is relevant as Khalil et al. (38) have postulated that a non-neurogenic factor (possibly insulin) may act on the adrenal gland to produce epinephrine during hypoglycemia in rats. This has recently been questioned as LaMarche et al. (39) have demonstrated that an intact innervated adrenal gland (i.e., central nervous system control) is required for epinephrine secretion in response to hypoglycemia. In addition, Donovan et al. (40) have reported that hepatic glucoreceptors are implicated in the catecholamine response to hypoglycemia. In the present study, however, systemic glycemia and insulin levels were identical during both protocols, thereby precluding differential hepatic (afferent) sensing as the explanation of our findings. It has also been suggested that under some circumstances, e.g., exercise, an increased rate of glucose utilization in muscle may set up a reflex increase in glucose production (41) to keep supply and demand equalized. In the present study differential glucose utilization rates by muscle could not explain the re- 
Table II. Effects of Head $(n=8)$ and Peripheral $(n=7)$ Insulin Infusions (2 mU/kg per min) and the Resulting Hypoglycemia (58 \pm 2 $\mathrm{mg} / \mathrm{dl}$ ) on Net Hepatic Glucose Balance (mg/kg per min) in Overnight-fasted Conscious Dogs

\begin{tabular}{|c|c|c|c|c|c|c|c|}
\hline & \multirow[b]{2}{*}{ Control period } & \multicolumn{6}{|c|}{ Duration of hypoglycemia (min) } \\
\hline & & 30 & 60 & 90 & 120 & 150 & 180 \\
\hline Peripheral infusion & $2.0 \pm 0.4$ & $1.2 \pm 0.3$ & $1.4 \pm 0.3$ & $3.0 \pm 0.5$ & $2.7 \pm 0.8$ & $2.5 \pm 0.6$ & $2.5 \pm 0.7$ \\
\hline Head infusion* & $1.9 \pm 0.3$ & $1.4 \pm 0.2$ & $4.4 \pm 1.0^{*}$ & $4.2 \pm 0.5 *$ & $4.1 \pm 0.7 *$ & $4.1 \pm 0.7 *$ & $3.9 \pm 0.5$ \\
\hline
\end{tabular}

Control period values are average of three measurements made during basal period in each dog. ${ }^{*}$ Head infusion values are significantly increased $(P<0.02)$ compared to peripheral infusion values.

sponse as glucose utilization was indistinguishable in the two protocols. Similarly, as peripheral insulin levels were identical, a potentially equivalent systemic vasodilatory stimulus would have been present in each protocol. In fact, mean arterial and diastolic blood pressure were lower during peripheral insulin than head insulin infusion ruling out a greater hypotensive signal being the cause of the augmented neuroendocrine response.

The present results clearly demonstrate that during hypoglycemia insulin can regulate the response of hormones and neurotransmitters released from peripheral tissues. Our results, on the other hand, do not provide any direct evidence that increased head levels of insulin can amplify release of pituitary hormones during hypoglycemia. However, as plasma cortisol levels were amplified during head insulin infusion, this would suggest that ACTH levels were also amplified during these experiments. This appears a reasonable speculation as $(a)$ we are not aware of any other normal physiologic mechanism for cortisol secretion other than by pituitary derived ACTH, and $(b)$ it is highly unlikely that under conditions of equivalent systemic hypoglycemia and insulinemia that adrenal gland sensitivity to ACTH could have been amplified or cortisol clearance could have been reduced during head compared with peripheral insulin infusion. Interestingly, we have data in man which supports the fact that insulin can regulate the release of pituitary hormones during hypoglycemia. In our previous studies growth hormone levels were amplified during hypoglycemia induced in the presence of high compared to lower levels of insulin $(16,41 \mathrm{a})$. Thus, it appears likely that, during hypoglycemia, insulin can regulate the response of both central and peripherally released neuroendocrine hormones.

The brain has been previously demonstrated to play the central role in coordinating the counterregulatory response to hypoglycemia (22). A lowered circulating glucose level is known to be the paramount signal for the neuroendocrine response. However, this study, supported by a number of indirect studies in man (16-18) demonstrates that insulin per se can regulate the counterregulatory response to hypoglycemia. Although the present study was performed in conscious dogs, we believe that our conclusions can be extrapolated to man. The counterregulatory response to hypoglycemia in dogs is, with

Table III. Effects of Head $(n=8)$ and Peripheral $(n=7)$ Insulin Infusions ( $2 \mathrm{mU} / \mathrm{kg}$ per min) and the Resulting Hypoglycemia on Arterial Levels of Blood Lactate, Alanine, Glycerol, 3-Hydroxybutyrate, Aceto-Acetate, and Plasma NEFA

\begin{tabular}{|c|c|c|c|c|c|c|c|}
\hline & \multirow[b]{2}{*}{ Control period } & \multicolumn{6}{|c|}{ Duration of hypoglycemia (min) } \\
\hline & & 30 & 60 & 90 & 120 & 150 & 180 \\
\hline \multicolumn{8}{|l|}{ Blood lactate $(\mu \mathrm{M})$} \\
\hline Peripheral infusion & $800 \pm 122$ & $720 \pm 88$ & $660 \pm 84$ & $897 \pm 196$ & $1033 \pm 285$ & $1105 \pm 309$ & $1171 \pm 311$ \\
\hline Head infusion ${ }^{\ddagger}$ & $958 \pm 159$ & $1022 \pm 136^{\ddagger}$ & $2143 \pm 351^{\ddagger}$ & $2811 \pm 521^{\ddagger}$ & $3383 \pm 608^{\ddagger}$ & $3351 \pm 728^{\ddagger}$ & $2980 \pm 626^{\ddagger}$ \\
\hline \multicolumn{8}{|l|}{ Blood alanine $(\mu \mathrm{M})$} \\
\hline Peripheral infusion & $354 \pm 51$ & $327 \pm 39$ & $240 \pm 22$ & $213 \pm 23$ & $191 \pm 24$ & $177 \pm 24$ & $161 \pm 21$ \\
\hline Head infusion & $401 \pm 33$ & $305 \pm 23$ & $268 \pm 17$ & $236 \pm 24$ & $251 \pm 32$ & $239 \pm 27$ & $223 \pm 27$ \\
\hline \multicolumn{8}{|l|}{ Blood glycerol $(\mu \mathrm{M})$} \\
\hline Peripheral infusion & $70 \pm 21$ & $50 \pm 14$ & $120 \pm 19$ & $159 \pm 20$ & $190 \pm 26$ & $215 \pm 29$ & $222 \pm 19$ \\
\hline Head infusion ${ }^{\ddagger}$ & $102 \pm 20$ & $133 \pm 30^{\ddagger}$ & $317 \pm 50^{* *}$ & $387 \pm 61^{\ddagger}$ & $447 \pm 77^{\ddagger}$ & $496 \pm 75^{\ddagger}$ & $458 \pm 82^{\ddagger}$ \\
\hline \multicolumn{8}{|l|}{ Plasma NEF $(\mu \mathrm{M})$} \\
\hline Peripheral infusion & $714 \pm 100$ & $367 \pm 73$ & $763 \pm 195$ & $880 \pm 136$ & $836 \pm 177$ & $873 \pm 129$ & $913 \pm 121$ \\
\hline Head infusion* & $774 \pm 123$ & $738 \pm 151^{*}$ & $1398 \pm 167^{*}$ & $1275 \pm 156^{*}$ & $1159 \pm 121^{*}$ & $1043 \pm 158^{*}$ & $1044 \pm 168$ \\
\hline \multicolumn{8}{|c|}{ Blood 3-hydroxybutrate $(\mu \mathrm{M})$} \\
\hline Peripheral infusion & $15 \pm 2$ & $7 \pm 2$ & $11 \pm 2$ & $14 \pm 2$ & $16 \pm 4$ & $16 \pm 2$ & $17 \pm 3$ \\
\hline Head infusion & $19 \pm 2$ & $11 \pm 2$ & $28 \pm 4$ & $24 \pm 3$ & $22 \pm 2$ & $23 \pm 4$ & $26 \pm 5$ \\
\hline \multicolumn{8}{|c|}{ Blood aceto acetate $(\mu \mathrm{M})$} \\
\hline Peripheral infusion & $83 \pm 10$ & $89 \pm 7$ & $94 \pm 5$ & $93 \pm 4$ & $93 \pm 9$ & $87 \pm 7$ & $83 \pm 6$ \\
\hline Head infusion & $69 \pm 7$ & $67 \pm 7$ & $73 \pm 7$ & $63 \pm 10$ & $68 \pm 7$ & $70 \pm 9$ & $72 \pm 13$ \\
\hline
\end{tabular}

Control period values are average of three measurements made during basal period in each dog. ${ }^{*}$ Head infusion values significantly greater $(P$ $<0.05)$ compared with peripheral values. ${ }^{\ddagger}$ Head infusion values significantly greater $(P<0.001)$ compared with peripheral values. 
Table IV. Effect of Head $(n=8)$ and Peripheral $(n=7)$ Insulin Infusions (2 mU/kg per min) and the Resulting Hypoglycemia (58 \pm 2 $\mathrm{mg} / \mathrm{dl}$ ) on Net Hepatic Uptake of Various Metabolites in Overnight-fasted Conscious Dogs

\begin{tabular}{|c|c|c|c|c|c|c|c|}
\hline & \multirow[b]{2}{*}{ Control period } & \multicolumn{6}{|c|}{ Duration of hypoglycemia (min) } \\
\hline & & 30 & 60 & 90 & 120 & 150 & 180 \\
\hline \multicolumn{8}{|c|}{ Lactate ( $\mu \mathrm{mol} / \mathrm{kg}$ per $\mathrm{min})$} \\
\hline Peripheral infusion & $-12.5 \pm 5.0$ & $-11.5 \pm 4.6$ & $-1 \pm 5.8$ & $5.7 \pm 2.2$ & $7.0 \pm 1.9$ & $7.4 \pm 2.6$ & $8.7 \pm 2.2$ \\
\hline Head infusion ${ }^{\ddagger}$ & $-8.0 \pm 3.0$ & $-5.8 \pm 2.2$ & $15.2 \pm 3.5^{\ddagger}$ & $21.7 \pm 4.0^{\ddagger}$ & $25.7 \pm 5.8^{\ddagger}$ & $25.4 \pm 3.4^{\ddagger}$ & $25.5 \pm 4.5^{\ddagger}$ \\
\hline \multicolumn{8}{|c|}{ Alanine $(\mu \mathrm{mol} / \mathrm{kg}$ per $\min )$} \\
\hline Peripheral infusion & $2.9 \pm 0.4$ & $3.0 \pm 0.6$ & $3.5 \pm 0.4$ & $2.9 \pm 0.4$ & $2.9 \pm 0.4$ & $2.8 \pm 0.4$ & $2.8 \pm 0.5$ \\
\hline Head infusion ${ }^{\ddagger}$ & $2.8 \pm 0.3$ & $3.5 \pm 0.4$ & $4.7 \pm 0.5^{\ddagger}$ & $5.3 \pm 0.8^{\ddagger}$ & $6.1 \pm 1.0^{\ddagger}$ & $6.2 \pm 1.1^{\ddagger}$ & $5.4 \pm 0.8^{\ddagger}$ \\
\hline \multicolumn{8}{|c|}{ Glycerol ( $\mu \mathrm{mol} / \mathrm{kg}$ per $\mathrm{min})$} \\
\hline Peripheral infusion & $2.0 \pm 0.9$ & $1.1 \pm 0.4$ & $3.3 \pm 0.7$ & $4.5 \pm 0.8$ & $4.2 \pm 1.0$ & $5.0 \pm 1.2$ & $5.0 \pm 1.1$ \\
\hline Head infusion ${ }^{\ddagger}$ & $1.9 \pm 0.4$ & $2.9 \pm 0.8^{\ddagger}$ & $8.6 \pm 2.5^{\ddagger}$ & $12.8 \pm 3.4^{\ddagger}$ & $15.2 \pm 4.8^{\ddagger}$ & $14.8 \pm 3.8^{\ddagger}$ & $12.8 \pm 2.3^{\ddagger}$ \\
\hline \multicolumn{8}{|c|}{ NEFA $(\mu \mathrm{mol} / \mathrm{kg}$ per min $)$} \\
\hline Peripheral infusion & $2.3 \pm 0.5$ & $1.4 \pm 0.5$ & $3.0 \pm 1.3$ & $4.9 \pm 0.9$ & $4.0 \pm 0.8$ & $3.2 \pm 1.0$ & $3.5 \pm 1.0$ \\
\hline Head infusion ${ }^{\ddagger}$ & $3.2 \pm 0.8$ & $4.1 \pm 1.4^{\ddagger}$ & $11 \pm 1.9^{\ddagger}$ & $9.4 \pm 2.9^{\ddagger}$ & $10.1 \pm 1.7^{\ddagger}$ & $9.8 \pm 2.6^{\ddagger}$ & $8.7 \pm 2.1^{\ddagger}$ \\
\hline \multicolumn{8}{|c|}{ 3-hydroxybutyrate $(\mu \mathrm{mol} / \mathrm{kg}$ per $\mathrm{min})$} \\
\hline Peripheral infusion & $0.8 \pm 0.2$ & $0.5 \pm 0.2$ & $0.7 \pm 0.1$ & $0.8 \pm 0.1$ & $0.7 \pm 0.1$ & $0.7 \pm 0.1$ & $0.8 \pm 0.2$ \\
\hline Head infusion ${ }^{\ddagger}$ & $1.1 \pm 0.4$ & $0.7 \pm 0.1$ & $2.4 \pm 1.1^{\ddagger}$ & $3.2 \pm 1.4^{\ddagger}$ & $2.2 \pm 0.6^{\ddagger}$ & $2.7 \pm 1.0^{\ddagger}$ & $3.2 \pm 1.4^{\ddagger}$ \\
\hline \multicolumn{8}{|c|}{ Aceto Acetate ( $\mu \mathrm{mol} / \mathrm{kg}$ per $\mathrm{min})$} \\
\hline Peripheral infusion & $1.0 \pm 0.35$ & $0.5 \pm 0.2$ & $0.9 \pm 0.2$ & $0.7 \pm 0.2$ & $0.8 \pm 0.2$ & $1.0 \pm 0.4$ & $0.9 \pm 0.3$ \\
\hline Head infusion ${ }^{\ddagger}$ & $1.0 \pm 0.3$ & $0.9 \pm 0.1^{\ddagger}$ & $1.7 \pm 0.8^{\ddagger}$ & $1.2 \pm 0.4^{\ddagger}$ & $1.7 \pm 0.3^{\ddagger}$ & $1.8 \pm 0.6^{\ddagger}$ & $2.1 \pm 1.0^{\ddagger}$ \\
\hline
\end{tabular}

Negative rates of net hepatic uptake indicate net hepatic production. ${ }^{\ddagger}$ Head infusion values significantly greater $(P<0.001)$ compared with peripheral values.

the exception of the growth hormone response, qualitatively similar to man. The effects of insulin on the autonomic nervous system under hypoglycemic conditions have also been demonstrated to be similar in the two species $(15-16)$. Thus the present finding may explain observations made in man concerning possible effects of insulin on the central nervous system. Kerr et al. (42) have reported increased cerebral blood flow during hyperinsulinemic euglycemia in normal man and Luzi et al. (43) have described an absence of the usual endogenous insulin suppression during hyperinsulinemic euglycemic clamps in denervated pancreatic transplanted IDDM subjects.

The increased metabolic and cardiovascular responses observed during the last $2 \mathrm{~h}$ of head insulin infusion are probably explained by amplified autonomic sympathoadrenal activity. Despite equivalent hepatic insulin and glucagon levels, the increased catecholamine levels (via circulation or neural input) was associated with a virtual doubling of hepatic glucose production during head insulin infusion. The increased HGP rate measured by tracer methodology was confirmed by direct net hepatic A-V difference data. The rates of glucose utilization $(4.3 \pm 0.3$ vs. $4.6 \pm 0.5 \mathrm{mg} / \mathrm{kg}$ per $\mathrm{min})$ and clearance rates ( $7.6 \pm 0.6$ vs. $7.8 \pm 0.7 \mathrm{ml} / \mathrm{kg}$ per $\mathrm{min}$ ) were similar during both insulin infusion protocols despite the greatly increased catecholamine levels during head insulin infusion. The finding that the excess catecholamines did not further reduce glucose utilization during head infusion may be explained by the fact that only moderate increments in epinephrine and norepinephrine are required to maximally suppress insulin stimulated glucose clearance. Stevenson et al. (44) have demonstrated, in the dog, that the dose related effects of epinephrine to reduce glucose clearance reach a maximum at circulating levels of $\sim 440 \pm 70 \mathrm{pg} / \mathrm{ml}$ (well below levels of $792 \pm 198 \mathrm{pg} / \mathrm{ml}$ observed in the peripheral insulin studies). Furthermore previous in vitro studies (45) have demonstrated that epinephrine's effects on reducing glucose clearance in skeletal muscle plateau at concentrations of $10^{-9}$ $10^{-8} \mathrm{M}$. These levels are very similar to the epinephrine levels reported by Stevenson et al. (44) in vivo. Thus, it appears clear that levels of epinephrine within the lower physiologic range exert a maximal effect on restraining glucose clearance. The mechanisms involved in epinephrine's action to suppress glucose clearance are not fully understood. However, recent work (46) has demonstrated that epinephrine may inhibit glucose clearance, in part, due to an increase in glucose-6-phosphate which in turn inhibits hexokinase.

Interestingly, there were differences in the source of glucose released by the liver during the head and peripheral insulin infusions. During the last hour of the present experiments, the initial glycogenolytic burst in response to hypoglycemia had waned and gluconeogenesis represented the process by which the elevated hepatic glucose production was sustained. In the head infusion group the minimal and maximal estimates of gluconeogenesis were 2.5 and $4.3 \mathrm{mg} / \mathrm{kg}$ per min, respectively. During the last hour of peripheral insulin infusion studies these estimates were 0.8 and $1.8 \mathrm{mg} / \mathrm{kg}$ per min. Thus gluconeogenesis was quantitatively more important during the head insulin infusions. As glucagon levels were similar during the last $2 \mathrm{~h}$ of both protocols this indicates that either the increased catecholamines and/or cortisol were responsible for the increased gluconeogenic rate when insulin was given into the head. Recently, Goldstein et al. (47) have demonstrated that an acute increase in physiologic levels of cortisol resulted in a very modest increase in gluconeogenesis. Thus the increased gluconeogenesis present in the head insulin infusions was probably due to the amplified catecholamine levels. Intrahepatic gluconeogenic efficiency, however, increased similarly regardless of the site of insulin infusion $(25 \pm 9$ to $53 \pm 9 \%$ head vs. $20 \pm 8$ to 


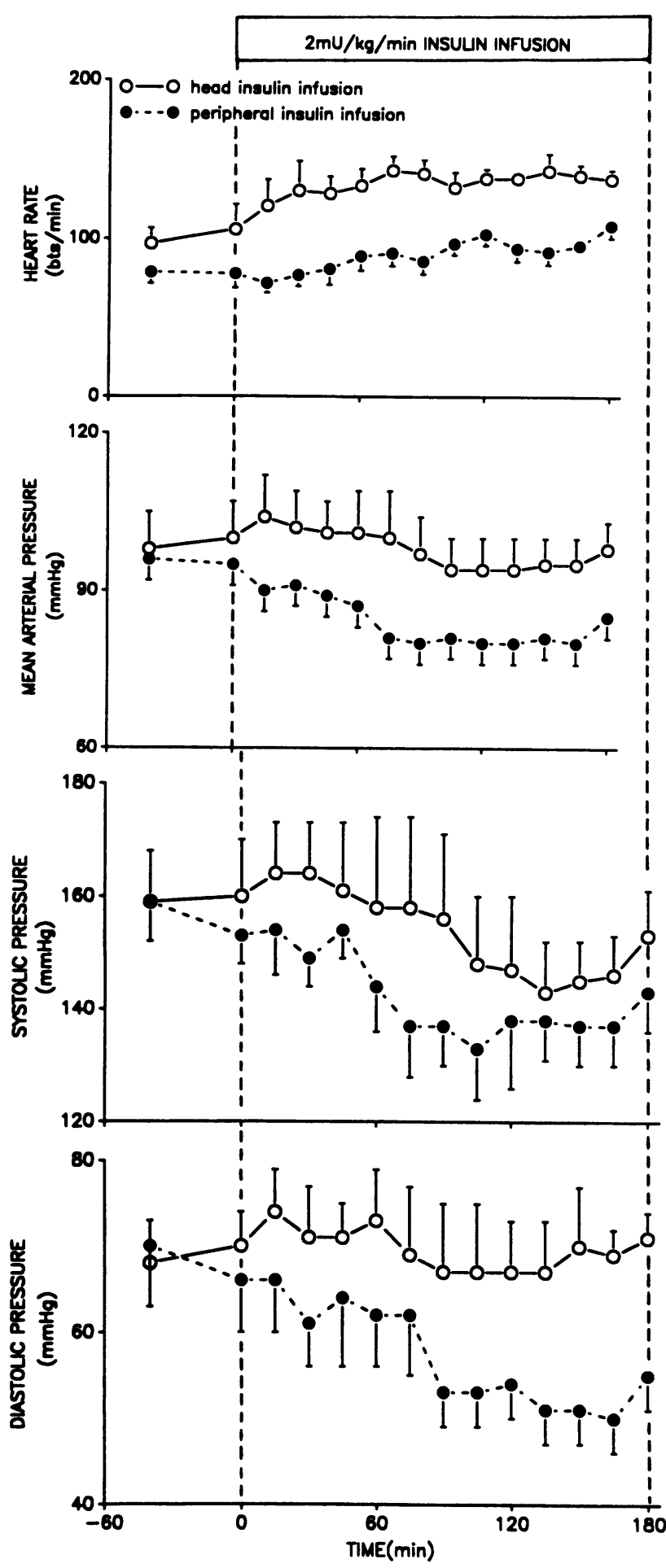

Figure 5. Effects of $2 \mathrm{mU} / \mathrm{kg}$ per min insulin infusions delivered either into both carotid and vertebral arteries (head insulin level 195 $\pm 5 \mu \mathrm{U} /$ $\mathrm{ml}$ ) or a peripheral vein (insulin level $86 \pm 6 \mu \mathrm{U} / \mathrm{ml}$ ) in the presence of hypoglycemia on heart rate, mean arterial, systolic, and diastolic blood pressure. Head values for heart rate, mean arterial and diastolic blood pressure are significantly increased $(P<0.05)$ compared with peripheral values.

$44 \pm 8 \%$ peripheral). Thus indicating that the increase in gluconeogenesis observed during head insulin infusion probably resulted from a greater substrate release by peripheral tissues (muscle and adipose tissue) rather than an effect at the liver per se. This supports previous studies in dogs (44) and humans (48) indicating that catecholamines have only a modest gluconeogenic effect on the liver directly, but have a marked peripheral action.

Lipolysis is very sensitive to inhibition by insulin. Circulating insulin levels of $\simeq 85 \mu \mathrm{U} / \mathrm{ml}$ when occurring in the presence of euglycemia, profoundly suppress lipolysis (49). Despite this, lipolysis, as indicated by the blood glycerol level, increased about fivefold in response to hypoglycemia during head insulin infusion and about threefold during peripheral insulin infusion. Circulating non-esterified fatty acid levels (NEFA) also increased to a greater extent during head insulin infusion. Net hepatic uptake of glycerol was greater during head insulin infusion (sevenfold above basal) compared to peripheral infusion (increase of 2.5-fold). Similarly net hepatic uptake of NEFA was also significantly greater during head (threefold) compared with peripheral insulin infusion ( $50 \%$ increase). The increased lipolytic rate occurring during hypoglycemia has been shown to be an important part of the counterregulatory response (50). The present data highlight the role of glycerol as an important gluconeogenic substrate during hypoglycemia. In addition the effects of increased NEFA levels at the periphery will tend to reduce glucose utilization by substrate competition and will provide energy at the liver for the gluconeogenic process. In association with the increase in NEFA uptake by the liver, ketogenesis (defined as the sum of acetoacetate and 3-hydroxybutyrate production) was also significantly increased during head (twofold) compared with peripheral infusion. The increased lipolytic and ketogenic responses, observed when the head insulin level was raised, are most likely explained by the elevated catecholamine levels and emphasize the potent metabolic effects of activation of the sympathetic nervous system. Despite increased ketogenesis during the head insulin infusions, circulating ketone levels were similar during both limbs of the study. Since steady state blood ketone levels existed, this indicates that the rate of ketone body utilization must have increased during head insulin infusion. These findings would be consistent with previous data demonstrating increased brain utilization of ketone bodies during hypoglycemia (51). Ketones have been suggested to reduce the autonomic nervous system's (ANS) response to hypoglycemia by supplying an alternative fuel to the brain (52). Thus it is possible that the ANS response during the head infusions may have been somewhat reduced due to increased brain ketone utilization. This further reinforces the magnitude of the effect of head insulin administration.

Insulin is proposed to gain access to the brain via three different routes $(a)$ a saturable transport system across the blood brain barrier; $(b)$ diffusion across the blood brain barrier; and (c) directly into brain areas lacking the blood brain barrier (9, $53,54)$. The exact site of insulin sensing by the CNS is not known. However, as the responses of the autonomic nervous system and the hypothalamo-pituitary-adrenal response (cortisol) were amplified, it appears that the hypothalamus was either directly stimulated by insulin or that it was secondarily stimulated by other areas of the brain with pathways projecting into it. The cellular mechanisms responsible for insulin's metabolic effects on the brain are not fully ellucidated (54). Recent work has demonstrated that insulin may directly increase noradrenergic turnover within the brain by inhibiting norepinephrine uptake in the synaptic cleft (55). However, data concerning insulin's action on brain glucose and glycogen metabolism are in conflict, with reports which show either no effect or increased 
Table V. Effects of Head $(n=8)$ and Peripheral $(n=7)$ Insulin Infusions (2 mU/kg per min) and the Resulting Hypoglycemia (58 \pm 2 $\mathrm{mg} / \mathrm{dl}$ ) on the Minimum Efficiency (\%) of Conversion of Plasma Alanine and Lactate into Glucose in Conscious Overnight-fasted Dogs

\begin{tabular}{lccccccc}
\hline & & \multicolumn{5}{c}{ Duration of hypoglycemia (min) } \\
\cline { 2 - 7 } & Control period & 30 & 60 & 90 & 120 & 150 & 180 \\
\hline Peripheral infusion & $20 \pm 7$ & $22 \pm 7$ & $32 \pm 5^{*}$ & $40 \pm 11^{*}$ & $44 \pm 6^{*}$ & $51 \pm 8^{*}$ & $43 \pm 3^{*}$ \\
Head infusion & $22 \pm 8$ & $29 \pm 10$ & $43 \pm 11^{*}$ & $48 \pm 9^{*}$ & $48 \pm 8^{*}$ & $51 \pm 9 *$ & $54 \pm 9^{*}$ \\
\hline
\end{tabular}

* Values are significantly greater $(P<0.01)$ than control period values from 60 min onwards.

action $(4,56)$. Confounding the interpretation of a number of the earlier studies is the fact that the glucose level was not controlled. This created two variables (insulin and hypoglycemia) which precluded mechanistic interpretation of the data. Additionally, the methods used to calculate cerebral glucose metabolism are model dependent and as such have been the source of much debate $(57,58)$. The unique advantage of the present study is that we were able to selectively subject the brain of the conscious dog to a physiologic increase in the circulating insulin level under controlled conditions. The significance of this finding extends beyond protection from hypoglycemia to control of obesity and nutrient intake. Considerable recent work (54) has demonstrated that under certain conditions insulin appears to have a crucial central role (i.e., brain) in regulating appetite and weight gain. The present data would strongly support the proposed theory that physiologic insulinemia can regulate energy balance via a direct influence on the central nervous system (54).

The present results also clarify the controversy concerning whether insulin per se can stimulate the sympathetic nervous system. Several studies have demonstrated increased cortisol and/or norepinephrine release by insulin under euglycemic conditions $(15,19,20,37)$. These data coupled with microneurographic studies demonstrating increased sympathetic nerve activity during hyperinsulinemic euglycemia have provided a consensus that insulin can activate the sympathetic nervous system during euglycemic conditions. The situation during hyperinsulinemic hypoglycemic conditions has not been resolved. Although several studies $(15,16,17)$ have reported amplification of the sympathetic nervous system by insulin during hypoglycemia, others have not $(59,60)$. In fact one study has reported a suppression of epinephrine by insulin during hypoglycemic conditions (61). There have been many differences in the design of the studies evaluating the effects of insulin per se during hypoglycemia. These have included $(a)$ differing depth of hypoglycemia, $(b)$ differing insulin levels, $(c)$ differing duration of hypoglycemia, $(d)$ prior hypoglycemic or hyperinsulinemic euglycemic periods, and (e) statistical power. It is, therefore, likely that the greatly varying experimental designs, in the above studies, has been the cause of much of the inconsistent data. The present results clearly answer two questions. First, they definitively support the finding that raised insulinemia in the brain can dramatically amplify the autonomic nervous system's counterregulatory response to hypoglycemia. Second, they demonstrate that increased physiologic insulinemia is sensed by the brain and as a result a large systemic increase in hormone secretion occurs and fuel mobilization is triggered.

In summary, these studies demonstrate that in the conscious normal dog, the brain is an insulin responsive organ. This finding is relevant since under hypoglycemic conditions the brain sensed a physiologic increase in blood borne insulin and as a result amplified the autonomic nervous system's counterregulatory response. This raises the possibility that small changes in the insulin level, such as occur over the course of a normal day, may result in discernable and meaningful alterations in autonomic function. To conclude, we suggest that the brain should be added to the list of mammalian tissues that are known to be sensitive to the direct effects of insulin.

\section{Acknowledgments}

We thank Wanda Snead, Eric Allen, and Lisa Young for technical assistance. We are grateful to Dr. J. Jaspan and Bill Pugh for kindly measuring the pancreatic polypeptide levels reported in the manuscript. We also appreciate the expert secretarial assistance of Jo Ann Allsbrooks.

This work was supported by a grant from the Juvenile Diabetes Foundation International (JDFI), Diabetes Research and Training Center (grant 5 P60 AM20593-08) and a JDFI postdoctoral fellowship (S. N. Davis).

\section{References}

1. Goodner, C. J., and M. A. Berrie. 1977. The failure of rat hypothalamic tissue to take up labeled insulin in vivo or to respond to insulin in vitro. Endocrinology. 101:605-612.

2. Rafaelsen, O. J. 1961. Action of insulin on glucose uptake of rat brain slices and isolated rat cerebellum. J. Neurochem. 7:45-51.

3. Hom, F. G., C. J. Goodner, and M. A. Berrie. 1984. A $\left({ }^{3}\right.$ H) 2-Deoxyglucose method for comparing rates of glucose metabolism and insulin responses among rat tissues in vivo. Diabetes. 33:141-152.

4. Nelson, S. R., D. W. Schultz, J. V. Passonneau, and O. H. Lowry. 1968. Control of glycogen levels in brain. J. Neurochem. 15:1271-1279.

5. Daniel, P. M., E. R. Love, and O. E. Pratt. 1975. Insulin and the way the brain handles glucose. J. Neurochem. 25:471-476.

6. Clarke, D. W., F. T. Boyd, M. S. Kappy, and M. K. Raizada. 1984. Insulin binds to specific receptors and stimulates 2-Deoxyglucose uptake in cultured glial cells from rat brain. J. Biol. Chem. 259:11672-11675.

7. Havrankova, J., J. Roth, and M. Brownstein. 1979. Concentrations of insulin and insulin receptors in the brain are independent of peripheral insulin levels. $J$. Clin. Invest. 64:636-642.

8. Figlewicz, D. P., D. M. Dorsa, L. J. Stein, D. G. Baskin, T. Paquette, M. R. C. Greenwood, S. C. Woods, and D. Porte, Jr. 1985. Brain and liver insulin binding is decreased in Zucker rats carrying the 'fa' gene. Endocrinology. 117:1537-1543.

9. Pardridge, W., J. Eisenberg, and J. Yang. 1985. Blood-brain barrier insulin receptor. J. Neurochem. 44:1771-1778.

10. Pereda, S. A., J. W. Eckstein, and F. M. Aboud. 1962. Cardiovascular responses to insulin in the absence of hypoglycemia. Am. J. Physiol. 202:249252.

11. Szabo, O., and A. J. Szabo. 1972. Evidence for an insulin-sensitive receptor in the central nervous system. Am. J. Physiol. 223:1349-1353.

12. Szabo, A., I. Iguchi, P. D. Burleson, and O. Szabo. 1983. Vagotomy or atropine blocks hypoglycemic effect of insulin injected into ventromedial hypoglycemic nucleus. Am. J. Physiol. 244:E467-E471.

13. Coimbra, C., and R. Migliorini. 1986. Insulin-sensitive glucoreceptors in rat preoptic area that regular FFA mobilization. J. Physiol. 251:E703-E706.

14. Figliewicz, D. P., P. Szot, and M. R. C. Greenwood. 1990. Insulin stimu- 
lates inositol incorporation in hippocampus of lean but not obese Zucker rats. Physiol. Behav. 47:325-330.

15. Davis, S. N., C. Tarumi, R. Dobbins, D. Neal, and A. D. Cherrington. 1992. The effect of differing insulin levels on the counterregulatory response to equivalent hypoglycemia in conscious dogs. Am. J. Physiol. 263:E688-695.

16. Davis, S. N., R. E. Goldstein, J. Jacobs, L. Price, R. Wolfe, and A. D. Cherrington. 1993. The effect of differing insulin levels on the hormonal and metabolic responses to equivalent hypoglycemia in normal man. Diabetes. 42:263-272.

17. Kerr, D., M. Reza, N. Smith, and B. Leatherdale. 1991. Importance of insulin in subjective, cognitive and hormonal responses to hypoglycemia in patients with IDDM. Diabetes. 40:1057-1062.

18. Davis, M., M. Mellman, and H. Shamoon. 1993. Physiologic hyperinsulinemia enhances counterregulatory hormone responses to hypoglycemia in IDDM. J. Clin. Endocrinol. Metab. 76:1383-1385.

19. Anderson, E., P. Hoffman, T. Balon, C. Sinkey, and A. Mark. 1991. Hyperinsulinemia produces both sympathetic neural activation and vasodilation in normal humans. J. Clin. Invest. 87:2246-2252.

20. Berne, C., J. Fagius, T. Pollare, and P. Hjemdahl. 1992. The sympathetic response to euglycemic hyperinsulinemia. Diabetologia. 35:873-879.

21. Cherrington, A. D., H. Fuchs, R. W. Stevenson, P. E. Williams, K. G. M. M. Alberti, and K. E. Steiner. 1984. Effect of epinephrine on glycogenolysis and gluconeogenesis in conscious overnight-fasted dogs. Am. J. Physiol. 247:E137-144.

22. Biggers, D. W., S. H. Myers, D. Neal, R. Stinson, N. Cooper, J. Jaspan, P. Williams, A. D. Cherrington, and R. T. Frizzell. 1989. Role of brain in counterregulation of insulin-induced hypoglycemia in dogs. Diabetes. 38:7-16.

23. Defronzo, R., J. Tobin, and R. Andres. 1979. Glucose clamp technique: a method for quantifying insulin secretion and resistance. Am. J. Physiol. 237:E214-223.

24. Cherrington, A. D., W. Lacy, and J. L. Chiasson. 1978. Effect of glucagon on glucose production during insulin deficiency in the dog. J. Clin. Invest. 62:664667.

25. Lloyd, B., J. Barrin, P. Smythe, and K. G. M. M. Alberti. 1978. Enzymatic fluorometric continuous flow assays for blood glucose, lactate, pyruvate, alanine, glycerol and 3-hydroxybutyrate. Clin. Chem. 24:1724-1729.

26. Price, C. P., B. Lloyd, and K. G. M. M. Alberti. 1977. A kinetic spectrophotometric assay for rapid determination of acetoacetate in blood. Clin. Chem. 23:1893-1897.

27. Ho, R. J. 1970. Radiochemical assay of long chain fatty acids using ${ }^{63} \mathrm{~N}$ as tracer. Anal. Biochem. 26:105-113.

28. Aguilar-Parada, E., A. M. Eisentraut, and R. H. Unger. 1969. Pancreatic glucagon secretion in normal and diabetic subjects. Am. J. Med. Sci. 257:415419.

29. Wide, L. and J. Porath. 1966. Radioimmunoassay of proteins with the uses of sephadex-coupled antibodies. Biochim. Biophys. Acta. 130:257-260.

30. Causon, R., M. Caruthers, and R. Rodnight. 1982. Assay of plasma catecholamines by liquid chromatography with electrochemical detection. Anal. Biochem. 116:223-226.

31. Hagopian, W., E. Lever, D. Cen, D. Emmonoud, K. Polonsky, W. Pugh, A. Moosa, and J. Jaspan. 1983. Predominance of renal and absence of hepatic metabolism of pancreatic polypeptide in the dog. Am. J. Physiol. 245:171-177.

32. Lang, C., A. Bagby, J. Ferguson, and J. Spitzer. 1984. Cardiac outpu and redistribution of organ blood flow in hypermetabolic sepsis. Am. J. Physiol. 247:E362-369.

33. Wall, J., R. Steele, C. Debodo, and N. Altszuler. 1957. Effect of insulin on utilization and production of circulating glucose. Am. J. Physiol. 189:43-50.

34. Debodo R., R. Steele, N. Altszuler, A. Dunn, and J. Bishop. 1963. The hormonal regulation of carbohydrate metabolism: studies with ${ }^{14} \mathrm{C}$ glucose. Recent Prog. Horm. Res. 19:445-488.

35. Chiasson, J. L., J. Liljenquist, B. Sinclair-Smith, and W. Lacy. 1977 Gluconeogenesis: methodological approaches in vivo. Fed. Proc. 36:229-235.

36. Wahren, J., P. Felig, G. Ahlburg, and L. Jorfeldt. 1971. Glucose metabolism during leg exercise in man. J. Clin. Invest. 50:2713-2725.

37. Frizzel R. T., G. Henrick, D. Biggers, B. Lacy, P. Donahue, D. Green, K. Carr, P. Williams, R. Stevenson, and A. D. Cherrington. 1988. Role of gluconeogenesis in sustaining glucose production during hypoglycemia caused by continuous insulin infusion in conscious dogs. Diabetes. 37:749-759.

38. Khalil Z., P. Marley, and P. Livett. 1986. Elevation in plasma catecholamines in response to insulin stress is under both neuronal and non-neurona control. Endocrinology 119:59-67.

39. Lamarche L., Vamaguchi, F. Peronnet, and F. Guitard. 1992. Evidence against a humoral control mechanism in adrenal catecholamine secretion during insulin-induced hypoglycemia. Am. J. Physiol. 262:R659-665.

40. Donovan, C., J. Halter, and R. Bergman. 1991. Importance of hepatic glucoreceptors in sympathoadrenal response to hypoglycemia. Diabetes. 40:155158.

41. Jenkins A., D. Chisholm, D. James, K. Ho, and E. Kraegen. 1985. Exercise induced hepatic glucose is precisely sensitive to the rate of systemic glucose supply. Metabolism. 34:431-436.

41a. Davis, S. N., A. Cherrington, J. Jacobs, and L. Price. 1993. The effects of insulin on the counterregulatory response to equivalent hypoglycemia in normal females. Am. J. Physiol. 265:E680-689.

42. Kerr D., J. Stanley, M. Barron, R. Thomas, B. Leatherdale, and J. Pickard. 1993. Symmetry of cerebral blood flow and cognitive responses to hypoglycaemia in humans. Diabetologia. 36:73-78.

43. Luzi L., A. Baltezzah, G. Perseghin, E. Bianchi, S. Vergoini, A. Secchi, E. Rocca, D. Spotti, G. Ferrari, V. Carlo, and G. Pozza. 1992. Lack of feedback inhibition of insulin secretion in denervated humans pancreas. Diabetes. 41:16321639.

44. Stevenson, R., K. Steiner, C. Connolly, H. Fuchs, K. G. M. M. Alberti, P. Williams, and A. D. Cherrington. 1991. Dose related effects of epinephrine on glucose production in conscious dogs. Am. J. Physiol. 260:E363-370.

45. Sloan, I., P. Sawh, and I. Bihler. 1978. Influence of adrenalin on sugar transport in soleus, a red skeletal muscle. Mol. Cell. Endocrinol. 10:3-12.

46. Raz, I., A. Katz, and M. Spencer. 1991. Epinephrine inhibits insulinmediated glycogenesis but enhances glycolysis in human skeletal muscle. Am. J. Physiol. 260:E430-435.

47. Goldstein, R., G. Reed, D. Wasserman, P. Williams, B. Lacy, R. Buckspan, N. Abumrad, and A. D. Cherrington. 1992. The effect of acute elevations in plasma cortisol levels on alanine metabolism in the conscious dog. Metabolism. 41:1295-1303.

48. Sacca, L., C. Kigorito, M. Cicala, G. Corso, and R. Sherwin. 1983. Role of gluconeogenesis in epinephrine-stimulated hepatic glucose production in humans. Am. J. Physiol. 245:E294-302.

49. Davis, S. N., P. Butler, M. Brown, S. Beer, W. Sobey, I. Manning, P. Home, N. Hales, and K. G. M. M. Alberti. 1991. The effect of human proinsulin on glucose turnover and immediary metabolism. Metabolism. 40:953-961.

50. Fanelli, C., P. Defeo, F. Porcellati, G. Perriello, E. Torlone, R. Santeusanio, P. Brunnetti, and G. Bolli. 1992. Adrenergic mechanisms contribute to the late phase of hypoglycemic glucose counterregulation in humans by stimulating lipolysis. J. Clin. Invest. 89:2005-2013.

51. Flatt, J., G. Blackburn, G. Randers, and J. Stanbury. 1974. Effects of ketone body infusion on hypoglycemic reaction in postabsorptive dogs. Metabolism. 23:151-158.

52. Amiel, S., H. Archibald, G. Chusney, A. Williams, and E. Gale. 1991 Ketone infusion lowers hormonal responses to hypoglycaemia: evidence for acute cerebral utilization of a non-glucose fuel. Clin. Sci. 81:189-194.

53. Schwartz, M., A. Sipols, S. Kahn, D. Lattemann, G. Taborsky Jr., R. Berman, S. Woods, and D. Porte Jr. 1990. Kinetics and specificity of insulin uptake from plasma into cerebrospinal fluid. Am. J. Physiol. 259:E378-383.

54. Schwartz, M., D. Figlewicz, D. Baskin, S. Woods, and D. Porte, Jr. 1992 Insulin in the brain: a hormonal regulator of energy balance. Endocr. Rev. 13:387414

55. Figlewicz, D., P. Szot, P. Israel, C. Payne, and D. Dorsa. 1993. Insulin reduces norepinephrine transporter mRNA in vivo in rat locus Coeruleus. Brain Res. 602:161-164.

56. Crone, C. 1965. Facilitated transfer of glucose from blood into brain tissue J. Physiol. 181:103-113.

57. Hawkins, R., A. Mans, D. Davis, and R. DeJoseph. 1988. Comparison of $\left[{ }^{14} \mathrm{C}\right]$ glucose and $\left[{ }^{14} \mathrm{C}\right]$ deoxyglucose as tracers of brain glucose use. Am. J. Physiol. 254:E310-317.

58. Namba, H., G. Lucignani, A. Nehlig, C. Patlak, K. Pettigrew, C. Kennedy, and L. Sokoloff. 1987. Effects of insulin on hexose transport across blood-brain barrier in normoglycemia. Am. J. Physiol. 252:E299-303.

59. Lui, D., E. Moberg, D. Kollind, P. E. Lins, and U. Adamson. 1991. A high concentration of circulating insulin suppresses glucagon response to hypoglycemia in normal man. J. Clin. Endocrinol. \& Metab. 73:1123-1128.

60. Mellman, M., M. Davis, and H. Shamoon. 1992. Effect of physiologic hyperinsulinemia on counterregulatory hormone responses during hypoglycemia in man. J. Clin. Endocrinol. \& Metab. 75:1283-1297.

61. Diamond, M., L. Hallaman, K. Starick-Zych, T. Jones, M. Conolly-Howard, W. Tamborlane, and R. Sherwin. 1991. Suppression of counterregulatory hormone response to hypoglycemia by insulin per se. J. Clin. Endocrinol. \& Metab. 72:1388-1390. 